\title{
El sacrificio animal en la literatura mexicana: cuatro ejemplos
}

\author{
Animal Sacrifice \\ in Mexican Literature: Four Examples
}

\author{
Francisco Javier Hernández Quezada \\ Universidad Autónoma de Baja California \\ hernandezf71@uabc.edu.mx
}

\begin{abstract}
RESUMEN: En este artículo reflexionamos sobre cuatro escritores mexicanos que han abordado la temática del sacrificio animal: nos referimos a Ramón Rubín, Juan José Arreola, Héctor Aguilar Camín y Alberto Chimal. En general, nuestro planteamiento es el de que, en uno u otro caso, se plasman situaciones perjudiciales y desventajosas para el ente no humano, considerando las implicaciones sociales del rol que se le ha asignado a través del tiempo, ya sea en el marco de la acción simbólica o en el de la lógica productiva de la actualidad. Partiendo entonces de las reflexiones derridianas sobre la relación existente entre la humanidad y la fauna, comprendemos que en los escritores analizados la mención o el uso del animal muestra los alcances materiales de su sacrificio, especialmente cuando entran en juego cuestiones como la representación literaria del dolor o del sufrimiento físico. Es relevante afirmar, a la vez, que en este trabajo consideramos las reflexiones hechas por diversos autores que, desde la perspectiva filosófica o antropológica, se han detenido en los aspectos constitutivos del acto sacrificial, señalando el rol sugerente del animal justamente al concebirlo como parte importante de un acontecimiento cultural donde se manifiestan ceremonias trascendentales (René Girard) o ritos de paso que fortalecen el nexo grupal (Clifford Geertz).
\end{abstract}

\author{
Palabras Clave: \\ sacrificio; \\ animales; \\ literatura mexicana; \\ ritual; \\ modernidad.
}

ABSTRACT: In this article we take a general look at four Mexican authors who have tackled the subject of animal sacrifice: Ramón Rubín, Juan José Arreola, Héctor Aguilar Camín and Alberto Chimal. Our broad approach is that one way or the other harmful and disadvantageous situations are expressed for the non-hu- 
KEYWORDS:

Sacrifice;

Animals;

Mexican literature;

Ritual;

Modernity. man entity, considering the social implications of the role which has been assigned to it across time, be it in the symbolic act or in today's production logic. Departing from such Derridean considerations about the existing relationship between humans and fauna, it is evident that in the works of the authors analyzed, the topic or use of animals presents the material reach of their sacrifice, especially when the matter of the literary representation of pain or physical suffering comes into play. It is relevant at the same time to affirm that in this work we consider the reflections of several authors who, from a philosophic or anthropologic perspective, have delved into the fundamental aspects of the sacrificial act, pointing out the evocative role of the animal, rightly conceived as an important cultural event, wherein are manifested transcendental ceremonies (René Girard) or the rites of passage which strengthen the group's ties (Clifford Geertz).

\section{Introducción: animales y literatura}

En la historia de la literatura mexicana, la utilización del animal ha sido constante (Hernández Quezada 2014a: 15-16). En muchos sentidos, ha favorecido el registro artístico de situaciones particulares donde se enfatiza el valor de la relación del ser humano con éste o, en otras, su rol en el marco del orbe natural. Por lo general, se trata de una utilización cambiante, lo cual condiciona sobremanera que su protagonismo esté determinado por valoraciones precisas que ponderan y enaltecen sus rasgos (físicos, simbólicos...) o los deniegan y marginan como parte de un planteamiento limitador.

Para el presente trabajo, nos interesa enfocarnos en una variable literaria del uso del animal: aquella vinculada con su sacrificio o, para ser más precisos, con la violencia perpetrada contra él (contra su bios); variable que subraya los poderes ejercidos no sólo contra el animal sino también contra todo lo existente en su-nuestro derredor y que contribuye al deterioro tácito del mundo material, a su crisis integral. Puntualmente, nuestro argumento precisa la idea de que hay momentos singulares de la literatura 
mexicana en los cuales los escritores ahondan en el punto anterior a fin de brindar imágenes llamativas o que no pasan desapercibidas debido al nexo establecido con el sufrimiento del animal y su degradación física; esta temática muchas veces se minimiza, se hace a un lado, a causa de que en diferentes valoraciones el animal es un ente carente de importancia vital y, sin embargo, su utilización resulta programática.

Especialmente, en dicho tenor creemos que nombres como los de Ramón Rubín (1912-2000), Juan José Arreola (1918-2001), Héctor Aguilar Camín (1946) o Alberto Chimal (1970) resultan significativos; y ello no tanto porque prioricen el tema en cuestión de la misma manera o lo conviertan en el centro de sus intereses (cosa que sí sucede, en honor a la verdad, con Arreola y Chimal); sino más bien porque, por momentos, la utilización del animal favorece la comprensión de una perspectiva compleja de las cosas mediante la cual el sacrificio, el martirio, el uso del ser no humano se patentiza a cabalidad como parte de una serie de esquemas simbólicos importantes o que se deben de difundir al comunicar algún mensaje sobre nuestra identidad. Ciertamente, aludimos a una literatura que, sí, es verdad, revela diversos intereses, no sólo los de la fauna, pero que, al abordarla, le brinda un tratamiento especial o llamativo, a tal punto que resemantiza otras situaciones carentes de relación.

Creemos que cuando Jacques Derrida enfatiza la cuestión de que el seguimiento del animal conduce finalmente a la deconstrucción del edificio humano, viabiliza la posibilidad de comprender la fragilidad especista de muchas verdades. Planteando la idea de que la mirada del animal es la mirada del otro, capaz de violentar la estabilidad de lo "propio", el filósofo argumenta sobre el hecho de que los seres humanos habitualmente escondemos las similitudes mantenidas con el resto de las criaturas vivientes, en parte porque concebimos una suerte de coraza cultural, antropocéntrica, que cubre los rasgos de nuestra "desnudez"; una "desnudez" de origen, carente de implicaciones sustanciales para el resto de los entes no humanos, toda vez que ellos jamás están "desnudos", y la vestimenta es uno de los inventos más importantes que los hombres han concebido para mitigar "el pudor" (Derrida 2008: 19). En rigor, esta idea permite comprender las implicaciones de la experiencia humana con respecto a los animales, aludiendo que, al momento de establecer diferencias, di- 
chos seres resaltan debido a cuestiones como la determinación instintiva de sus impulsos o los procesos de sobrevivencia que tienen y les permiten desenvolverse con normalidad. El planteamiento, a la vez, refuerza la cuestión de un poderío intelectual que establece la lógica de proyectos sistémicos como el del culto al progreso o al de la razón, al partir de la idea de que no existe otro individuo que viva sobre la faz de la tierra con tales cualidades (el ser humano), desarrolladas, entre otras cosas, para atenuar las consecuencias materiales y simbólicas de la "desnudez"; o sea, de esa carencia original que marca la vida de las demás especies y que, sin duda, las somete a situaciones indeterminadas, carentes de control, como las que se suceden ordinariamente en el ámbito del mundo natural. Resumiendo, la prédica-asunción de la superioridad humana ha sido uno de los motores de la transformación histórica y, como sugiere Derrida, ha destinado a los animales a un lugar marginal o secundario, en el que lo "propio"-humano es inexistente y en el que, por si fuera poco, al entrar en contacto con ellos, se corre el riesgo de padecer "el acontecimiento desafortunado, la coincidencia, el vencimiento, la mala sombra" (2008: 18).

En este punto, la literatura ha planteado representaciones del animal que sostienen o refuerzan lo anterior, incluso cuando es el protagonista del texto y se describen detalladamente sus atributos físicos o psicomotrices. Si pensamos, luego, en formatos narrativos como los bestiarios, es fácil concluir que los argumentos ahí planteados fortalecen el rol activo del ser humano, especialmente porque las cualidades que se le atribuyen minimizan las del animal tras partir de un "pináculo ontológico en la jerarquización de los entes del universo" (Suárez, Carrera Aizpitarte y Anzoátegui 2018: 5-6).

Indudablemente, tal concepción da pie a fenómenos singulares que priorizan la representación del elemento fáunico, pero sólo para insistir en el ideal antropocéntrico, el mismo que justifica los procedimientos del yo racional y, además, establece discontinuidades y diferencias que solventan el relato especista de lo "propio". La animalidad, vista y tratada desde tal perspectiva, es una entidad menor, francamente ninguneada, que hace las veces de contraparte colectiva ideada para solventar la iteración de un rol: el del ser humano (el de sus poderes). Con este criterio, se insiste 
además en la prédica de la subordinación, del control de aquello que carece de estamentos antropocéntricos, toda vez que se parte del principio de una jerarquización, la cual determina cómo funcionan las cosas, el tipo de criterios a seguir, los esquemas de inclusión y exclusión, entre otras consideraciones referidas al definir el modelo social y aquello que, voluntaria e involuntariamente, escapa de él.

En el caso de las letras mexicanas, es cierto que la utilización de la fauna ha implicado un sinfín de matices, que van desde la representación elemental de esta entidad hasta aquella que, compleja, nos muestra la otra cara de la realidad. Semejante utilización refleja puntualmente valoraciones colectivas sobre el nexo ser humano-ser no humano, favoreciendo la plasmación de múltiples situaciones que enfatizan lugares comunes con respecto al deber ser de la animalidad, en conjunto, o, de modo contrario, que solventan y fortalecen la creación de imágenes vigorosas y singulares de esta condición.

Por lo tocante a la literatura mexicana del siglo $\mathrm{xx}$, la propuesta de Arreola es paradigmática: se trata de una visión estética que indaga en el universo de los animales de tal suerte que la estampa ofrecida de este conjunto de seres vale por su belleza, al tiempo que por su complejidad. Escritor que inaugura otra imagen "del prójimo desmerecido" (Arreola 1996: 9), como él lo denomina; devela los alcances de la "desnudez" en aras de violentar-fracturar los esquemas impuestos a través de los años, precisamente al minimizar su importancia en el devenir de la humanidad.

Si bien más adelante regresaremos a los argumentos de Arreola, es importante subrayar que la imagen de la animalidad, en nuestras letras, ha girado en torno a la contrastiva ser humano-ser no humano, en virtud de que los planteamientos hechos se han basado en el criterio especista de la superioridad del sujeto racional frente al resto de las especies; fenómeno Ilamativo, nos parece, que ha generado la apreciación de las diferencias existentes con estos entes, concebidos como sujetos manipulables o de fácil control; como sujetos secundarios, sometidos al avance de la civilización.

Sin embargo, y al mismo tiempo, la presencia del animal ha supuesto valoraciones contrastantes, alejadas del paradigma anterior, en el entendido de que las prioridades cambian entre un escritor y otro; dicha situación 
favorece que determinadas cuestiones se conciban de modo particular o vayan en contra de lo establecido como modelo a seguir. En esa dirección, aludimos al punto de que así como algunos autores minimizan el papel del animal, de acuerdo con su esquema calificativo, hay otros que se acercan a la realidad de éste, a su entorno, captando aquello que lo distingue en lo individual. Hablamos de un acercamiento problemático, pues antes que aceptar el deber ser de un paradigma, esquemático y determinista, se reiteran los criterios del arte, de la imaginación, amplificando los sentidos del universo material-animado y mostrando de ese modo una estampa divergente de lo animal, menos influida por el esquema unidireccional del mundo en el que nos desenvolvemos y más abierta y receptiva a los contrastes biológicos-vitales de nuestra realidad.

En función del planteamiento anterior, el nexo hombre-fauna engloba varias cuestiones: en principio, aquella que concibe al animal de forma provechosa, según los beneficios que genera y se relacionan con la alimentación, la materia prima, la fuerza laboral, etcétera. En esencia, aludimos a un nexo comercial y pragmático que ha garantizado el desenvolvimiento material de la humanidad, tal como lo conocemos en la actualidad, y que para la fauna ha significado lo contrario: su manipulación y control; esto es, su papel secundario en el avance de la civilización (cfr. Libonati 2017). A la par, dicho nexo presenta otra cuestión, insoslayable también en tal avance: nos referimos a la cuestión de la afectividad: inclinación personal que expresa el valor sentimental al animal más allá del fundamento privado o público que lo determine; y más allá, incluso, de los supuestos racionales que guían el trato con otros sujetos, y manifiestan el ingreso del ser humano en los terrenos problemáticos de "la coincidencia" fáunica-no humana, con las consabidas pérdidas del control y de la estabilidad que entraña (cfr. Hernández Quezada 2017). Igualmente, y a esto queremos Ilegar, una tercera cuestión es la de lo simbólico: cuestión literaria-creativa que pondera el significado del animal en el contexto de una significación cultural, vinculante y rectora.

Especialmente, dicho aspecto es el que nos interesa abordar en el presente artículo, tomando en cuenta los indicadores temáticos que conlleva y permiten pensar en la distinción-(dis)función del elemento fáunico. Por lo que, otra vez, entendemos que la significación del animal cobra espe- 
cial relevancia, pero no tanto por lo que implica, según la mirada solitaria del ser humano, sino más bien por lo que colige en términos colectivostrascendentales y, de acuerdo con el antropólogo Victor W. Turner, fortalece el proceso ritual de la "communitas" (1988: 103).

Elemento simbólico, que (inter)actúa a partir de lo preestablecido: anotemos pues que el animal humanizado potencia los valores del rito, o del ritual, luego de ser integrado a una representación colectiva, significante, en la que su bios es limitado-predeterminado antes de la experiencia. Y no sólo eso, también, luego de ser nombrado simbólica y metafóricamente (Ricœur 1998: 64), ya que la presencia o mención de lo animal borra las distancias de dos realidades incompatibles: la humana y la no humana. Huelga insistir: dos realidades separadas, en apariencia, pero entrecruzadas desde el momento en el que el escritor, mediante su trabajo, participa de lo extraño, de lo inusual, y da fe de cómo el sacrificio de uno (el animal no humano) garantiza la existencia de otro (el animal humano), situando figuradamente a las "víctimas [...] en el mismo plano" (Girard 1983: 19) de la representación que pretende difundir.

Por supuesto, un planteamiento como el anterior contrasta con el de la primera cuestión (el del beneficio material), en el sentido de que las valoraciones del animal son diferentes $y$, además, pautan ideas precisas que minimizan su rol. Por ende, ahí donde vemos una iteración del papel secundario, no complejo, de dicho ser, encontramos otra donde la propuesta protagónica del animal es real, pero concebida a partir de su uso sacrificial o de sus alcances nodales en el seno esquematizado de una ceremonia tanto individual como colectiva.

En todo caso, ejemplo puntual de la concepción secundaria del animal, sometida al desarrollo humano, lo vislumbramos en el libro Su nombre era Muerte (1947), del escritor Rafael Bernal (1915-1972): libro donde la animalidad, encarnada por los insectos, se concibe de forma negativa debido a lo que implica para los hombres; nos referimos a la enfermedad, a la destrucción, al caos.

Su nombre era Muerte refiere un discurso preciso que está a favor del bienestar social (en particular, el del proyecto moderno-occidental), lanzando el mensaje unívoco de que frente a los peligros de la animalidad es conveniente su erradicación y exterminio integrales, máxime si el objetivo 
buscado es que las condiciones de vida existentes no cambien para los seres humanos y sus esquemas de desarrollo se perpetúen por siempre. De ahí que se entienda que, para el planteamiento literario de Su nombre era Muerte, lo menos importante es la ideación simbólica o la visión trascendental del animal-insecto, en términos de que la concepción referida parte de la amenaza, del peligro total. Un peligro, para decirlo derridianamente, que colige el "vencimiento" y la postración y que, de acuerdo con el planteamiento hecho, debe combatirse a diestra y siniestra en pos de que los insectos desaparezcan por siempre y jamás invadan los terrenos fronterizos-controlados de la humanidad (cfr. Serratos 2017: 8).

Básicamente, Su nombre era Muerte ofrece una visión especista, ideada para solventar los argumentos creativos del relato, antes que para establecer un paradigma complejo de la animalidad. Sin que esto, en principio, deba cuestionarse, ya que funciona en el esquema creativo de Bernal (el de la ciencia ficción), resulta innegable que su concepción de los insectos se adecua a los requerimientos tradicionales del discurso salvífico, el cual gira en torno a la humanidad y, por consiguiente, se aleja de la imagen problemática del animal: imagen que, en otras circunstancias, daría pie a una indagación más curiosa en el universo contrastivo de lo menor, tal como lo hace Arreola en cuentos magistrales como "Insectiada" o "El prodigioso miligramo", al recrear las características de ese universo y mostrarnos una estampa más elaborada del mismo (Yurkiévich 1997: 201). En otro tenor, aunque amparado en una concepción parecida, se encuentra el cuento de Francisco Tario, "Ragú de ternera" (1968); cuento en el que la fauna es sinónimo de comida, de materia prima para subsistir, de acuerdo con la mirada incisiva de un caníbal, quien comenta que su progresión alimentaria parte de la ingesta de proteínas animales para, después, culminar en la deglución de carne no animal. Obviamente, como en el texto anterior, las implicaciones de la animalidad son irrelevantes, a no ser porque constituyen el punto de partida nutricional de un individuo que, en el mejor de los casos, concibe al ente no humano como ese basamento vital que le permite el paso alegórico a otro nivel. Se comprende, desde luego, que la concepción simbólica del animal aquí también carece de importancia, dado que lo relevante es la premisa que señala las etapas de la transformación del yo en un ser monstruoso, 
fundamentalmente en el momento de resumir los gustos caníbales que adquiere tras ingerir, con frecuencia, carne no humana (Ferrero Cárdenas 2009: 172). Entendamos, en sí, que la idea es ofrecer el relato de esa metamorfosis gracias a la cual el hombre se convierte en ente irracional, fuera de la ley, capaz de actuar como los animales y, por eso, capaz de violentar el edificio occidental de la civilización. Empero, volvemos a lo mismo: en "Ragú de ternera", el animal es carne, es comida, nada más. O peor todavía: el animal-caníbal es el peligro; la "mala sombra" derridiana a vencer.

Notoriamente, aquella literatura que pondera la imagen del sacrificio animal presenta otros alcances: ideada para dar fe de la lógica simbólica de un deber ser, focaliza su atención en las prácticas sociales que incluyen-administran una entrega, una claudicación, una muerte: la del ser no humano. Es por ese motivo que la representación estética del sacrificio se acerca a las valoraciones hechas por la antropología y los estudios religiosos, que establecen que

un objeto, un animal o un ser humano, es sustraído de su calidad profana para ser entregado a seres sobrenaturales. Se entiende que, de manera más particular, el término alude a la ofrenda cruenta que implica la muerte de un ser animado en el acto de consagrarlo a una divinidad [...] La noción de ofrenda es un componente esencial del concepto y, de hecho, está en la misma etimología del término latino del que deriva directamente nuestra palabra; sacrificium, significa literalmente "ofrenda a una divinidad" (Cabrera Díaz 2010: 49).

Es prioritario asimilar la idea de que, cuando la literatura mexicana trabaja este tema y establece nexos con el animal (en tanto ente "sustraído de su calidad profana"), prioriza la ejemplificación de una actividad humanacultural cuyo sentido integral sólo se comprende, o se comprende mejor, si se considera el contexto del cual surge y determina su concepción. En otras palabras, aludimos al planteamiento literario que utiliza la imagen precaria del animal con el objeto de expresar su rol en los entresijos de una trama simbólica, prevista para la consecución de un fin. Un rol ambiguo, anotamos, que la creación literaria enfatiza para demostrar algo más y que, por momentos, nos enfrenta con el animal entendido como ente sometido, puesto al servicio del proceso cultural. 


\section{El canto de la grilla o el "ritual estirado" del "borrego"}

La concepción sacrificial del animal como parte relevante y fundamental de una actividad simbólica es una de las tantas referencias antropológicas que el escritor Ramón Rubín presenta en El canto de la grilla (1985), novela que tardíamente se inscribe en la tradición vernácula del indigenismo, y en la que se engloban motivos culturales vinculados con las formas de vida de un grupo étnico. Centrada en la recreación de los usos y costumbres de los coras del estado de Nayarit (Jáuregui 2004), el autor describe imaginariamente un universo aparte, alejado de la sociedad mestiza, en el cual privan, de modo tajante, los esquemas simbólicos de la comunidad.

Sobre el planteamiento literario de Rubín, José María Espinasa (2016) ha escrito que este autor se distingue por el sólido y certero tratamiento de la condición humana, sin distinguir pertenencias raciales o étnicas que influyan en tal o cual proceder, ni mucho menos que los conviertan en entes manipulables, de fácil control, y que además les brinden un protagonismo menor, como sucede en otros casos. Siguiendo las ideas de Espinasa, consideremos que frente a las propuestas esquemáticas que soslayan la complejidad del sujeto, encontramos en Rubín a un escritor sensible que indaga conscientemente en la vida de los indígenas, dejando de lado banalidades interpretativas que desvalorizan la problemática del existir y, por lo mismo, profundizando de tal manera en la psicología de los personajes que lo que encontramos en ellos no es la proyección de las percepciones limitadas del autor sino la recreación de sus voces, de sus perspectivas del mundo.

Hablamos de sujetos literarios, tratados de modo dialógico, que interactúan libremente con sus congéneres y por ello manifiestan sus desacuerdos o visiones de las cosas, entrando en conflicto con el resto de la agrupación.

Ese realismo [...] no es el de una voluntad fotográfica; tiene más que ver con la interioridad de sus personajes, misma que se expresa — Rubín difícilmente habría pensado que se pudiera expresar de otra manera - en hechos exteriores, en tradiciones fruto de muchos años acumulados pero que no por ello dejan de ser bárbaras [...] Entendía que no bastaba reflejar la realidad tal cual era si no se le daba un matiz que le quitara su sentido unívoco (Espinasa 2016: 158). 
Ese "realismo", del cual habla Espinasa, es importante no perderlo de vista; es el recurso utilizado por Rubín para traer a colación la temática animal en los términos planteados: utilizarla como parte de un todo cultural que explica los significados de diversas prácticas simbólicas de los cora: grupo étnico que vive en el actual estado mexicano de Nayarit y que, de acuerdo con nuestro escritor, evidencia una concepción religiosa de las cosas donde se patentiza la necesidad social del sacrificio del ente no humano, según se observa en el siguiente párrafo, relacionado con la boda de los dos personajes principales del libro:

Se trajo al infeliz borrego cuyo sacrificio era parte importantísima del estirado ritual y se dispuso ante ellos. Los topiles le amarraron un cabo de ixtle a cada pata y jalando de éstas en dirección de los cuatro puntos cardinales lo despernancaron brutalmente. Hasta que, dando con la panza en el suelo, quedó distendido sobre él y casi descoyuntado de las articulaciones, doliéndose de su ingrata postura con un balido tímido y lastimero que no había de conmover el ánimo empedernido y soñoliento de sus verdugos (Rubín 1985: 88).

Tal como se señala en el párrafo, el animal es "parte importantísima" de un "estirado ritual" que, por encima de cualquier otro aspecto, lo violenta, lo disloca "brutalmente". Pero semejante hecho - que tal vez, en otras circunstancias, obligaría a los "verdugos" a apiadarse del "infeliz borrego" y por tanto a valorar su "sacrificio" - apenas si es tomado en cuenta, lo que explica que si el animal vale algo, o significa algo, es por su atadura al acto ceremonial: acto que, como plantea Clifford Geertz —al hablar de los "símbolos sagrados" —, sintetiza "el ethos de un pueblo" y su "cosmovisión, el cuadro que ese pueblo se forja de cómo son las cosas en la realidad, sus ideas más abarcativas acerca del orden" (1997: 89).

Así, en el presente caso, el "infeliz borrego" es "parte importantísima" de la anécdota; de acuerdo con la óptica del narrador-autor, el registro literario de su "sacrificio" resulta significativo para la comprensión del tipo de usos y costumbres que existen en muchas comunidades del país; a la vez, para la comprensión del papel del animal — de su papel histórico— en el marco desequilibrado de la relación humano-no humano. Por consiguiente, subrayamos que, con un párrafo como el anterior, Rubín abrevia el tormento del animal, nos pone en su piel, manifestando enorme sensibilidad 
y atracción por éste: enorme sensibilidad y atracción que, desde luego, se refleja en el tratamiento cuidadoso del "estirado ritual" y que, para parafrasear a Derrida, lo impulsa a describir "el sufrimiento, el miedo o el pánico, el terror o el pavor que puede apoderarse de algunos animales y del que nosotros, los hombres, podemos dar testimonio" (2008: 44). Insistimos: no es que Rubín se regodee en torno al dolor animal, sino más bien que propone la contraparte del mismo; digamos, la contraparte negada, no vista, soslayada, pues al tiempo que el escritor pormenoriza los detalles de una boda, con la descripción recurrente de sus motivos, la imagen del sacrificio animal viene y va.

No está de más decir que, en este caso, la historia que Rubín libera, discursivamente hablando, es la del animal: la historia de su sufrimiento, de su utilización o, si se prefiere, la historia del ente menor —la historia de lo menor-que, al ser recuperada, también violenta la práctica del ritual, la intensifica, ya que en todo esto el lector es consciente del papel del ente no humano; un papel que no pasa desapercibido, menos cuando se insiste en que el "infeliz borrego" media en el desarrollo de la interacción social, aunque pasivamente, como se lee en las siguientes líneas: "A un lado del animal, en dirección de su cabeza, se colocó Mateo [el personaje principal de la novela], asistido por su padre. Trájose luego a la novia, que trastabillaba al andar, y se la puso, por el contrario, hacia la cola, y asistida por su progenitor huichol, el cual, aunque previamente renunciara a ella resultaba indispensable para el buen orden de la ceremonia" (Rubín 1985: 88).

En resumen: la idea que se desprende del pasaje anterior es la de que el "infeliz borrego", finalmente, está ahí, en medio de todos, a la vista de todos; pero su posición, "con la panza en el suelo", despernancado, lo convierte en un ente superficial que sirve de parapeto entre los novios y, para el caso, en elemento postrado, "casi descoyuntado de las articulaciones", de una representación: de aquella en la que nadie se apiada del "corderito sometido a tan bárbara tortura", hasta que, pasado el tiempo (no se dice cuánto, pero suponemos que bastante), el "verdugo" corta "al rumiante en dos de un solo tajo" y los "intestinos del pobre animal saltaron por el aire, y su sangre salpicó a los más cercanos, sin que se inmutaran por ello. Antes bien, la cruel escena parecía llenar de un explosivo gozo el pecho de todos los congregados" (1985: 90-91). 
Siendo precisos, el tratamiento de un pasaje como este a Rubín le permite concebir un relato indigenista o etnográfico en el que la mención del animal es relevante por los alcances culturales-religiosos que tiene. O más bien explicado, en el que su uso favorece la descripción de una práctica colectiva, simbólica, concebida para detallar los hábitos históricos de una comunidad. Y es que, de acuerdo con lo argumentado líneas atrás, la figura del animal encarna el papel del ente sacrificial, del ente sometido, que es parte fundamental de una serie de prácticas religiosas, ideadas para rendir culto a la vida o para permitir su renovación y, en definitiva, "establecer vigorosos, penetrantes y duraderos estados anímicos y motivaciones en los hombres", según "un orden general de existencia" (Geertz 1997: 89).

Lo cierto es que, considerado el planteamiento literario de fondo (el del "sacrificio"), el aspecto festivo de dichas prácticas queda en segundo plano, en vista de que descubrimos que a Rubín le interesa dramatizar la imagen del animal; esto es, brindar una imagen del sufrimiento que dicho ser experimenta a partir de la descripción precisa de los hábitos sociales y, por lo tanto, de la mención de los procedimientos de control y sometimiento existentes con respecto al ente no humano.

En general, el escritor enfatiza el tormento físico del animal tras brindar una recreación detallada de su postración y, gracias a ello, de su participación pasiva, extática, en una actividad cultural que visiblemente lo segrega y convierte en elemento desechable, sacrificado-martirizado para el beneficio de los demás o, como afirmaría Geertz, para que "los estados anímicos y motivaciones parezcan de un realismo único" (1997: 89).

Por eso, es lógico pensar en que uno de los mensajes que se desprenden de El canto de la grilla refiere la singularidad cultural de los hábitos colectivos. Pero, al mismo tiempo, creemos que otro de los mensajes que se desprenden de esta novela gira en torno al sentido del animal, o mejor, de la interacción que mantiene con el hombre: interacción sugerente, enmarcada en la valía del hecho trascendental y que no obstante precisa su caída, su tragedia habitual.

Es evidente, por lo demás, que tal dejo animalsonante (Derrida 2008: 18) se expresa en el uso del lenguaje escrito, de modo que son constantes las veces en que Rubín se refiere al ser no humano con adjetivos como "infeliz", "tímido", "lastimero" y, al menos en el pasaje referido, que de los 
hombres-"verdugos" enfatice su "ánimo empedernido y soñoliento"... En fin, entendemos que el objetivo estético de Rubín, en El canto de la grilla, es claro y consiste en la ideación de un planteamiento literario donde si bien la lógica del registro del "estirado ritual" se patentiza y abona sobradamente al antropologismo de la narración, también abona a la comprensión del problema animal.

\section{Arreola y la concepción moderna del sacrificio animal}

Una variable de la literatura mexicana que, expresamente, reclama la conciencia del sufrimiento animal es la de Arreola: escritor que, para el caso, ha llevado hasta sus últimas consecuencias el sentido trágico de lo fáunico en el escenario sombrío y escatológico de la modernidad. Sin detenerse en el trabajo archivístico de índole antropológica que ata el devenir del no humano a las prácticas simbólicas de una comunidad, o evitando justificar culturalmente el porqué del sufrimiento de este ser, Arreola esgrime un sentido de lo animal que viabiliza diversas lecturas.

Especialmente, una de las que más nos hacen pensar en la animalsonancia de Arreola es la que pone el dedo en la llaga del sufrimiento fáunico: sufrimiento que contrasta con el de Rubín por cuanto se trata de la concienciación del devenir de este ser en el ámbito de un mundo racionalizado, donde el animal es sacrificado no necesariamente para el fortalecimiento de las "motivaciones humanas", vinculadas con lo sagrado, sino para la obtención de los beneficios económicos, educativos, sociales, propios de la sociedad actual.

Revisando cada una de las viñetas de Bestiario, es fácil comprender que, en el fondo, las motivaciones de Arreola se vinculan con el rescate de la complejidad animal; pero, al mismo tiempo, con el del sentido de su sacrificio, de su sacrificio cotidiano, especialmente si ponemos atención en los usos materiales del ser no humano, de acuerdo con la perspectiva de la industria, del mercado o de la ciencia. Efectivamente, planteamos la idea de que para Arreola las variables sufrientes del animal, en la actualidad, no hay que buscarlas en los actos ceremoniales de las sociedades originarias, que parecieran, en muchos casos, mantener vivas sus creencias 
ancestrales. Más bien, tales variables hay que verlas o descubrirlas en los ámbitos de la vida cotidiana, en los cuales, a diferencia de los pertenecientes al medio rural-indígena, se aprecia la valoración no trascendental del animal, la valoración precaria, concebida a partir de los márgenes de utilidad que genera y fortalecen el sistema de producción.

En Bestiario, Arreola formula el planteamiento anterior con el objeto de evidenciar la singularidad fáunica, a la vez que rebajar o poner en el mismo nivel a la humanidad. Consiguientemente, este planteamiento explica el dejo irónico de Arreola, ya que, desde su perspectiva, la supuesta preponderancia de la raza humana fácilmente se viene abajo cuando se alude al resto de los animales y se capta la precariedad de muchas de nuestras acciones. Crítico de la modernidad y del culto a la razón, mencionemos que Arreola abrevia principios altamente corrosivos, posibilitando un tipo de creación carnavalesca que habla de los animales con enorme y singular soltura, presentando el dinamismo de un universo propio, que bien vale la pena comprender en sus aspectos nimios y profundos (cfr. Hernández Loredo 2012). El planteamiento, por tanto, de una escritura desbordante que rebasa los límites trazados entre los hombres y los animales, se convierte en piedra de toque fundamental del ejercicio arreoliano y ello, más que limitar la concepción de los seres humanos o de encasillarlos en percepciones anodinas que minimizan las manifestaciones de su inestabilidad, conduce a proponer equivalencias entre los entes humanos y los no humanos. Y no sólo eso, también establece muchas diferencias entre ambos, las mismas que al final nos hacen pensar en las características distintivas de los animales, en su importancia ecosistémica.

De acuerdo con Arreola, el conocimiento de la humanidad pasa por el de los animales, por el de su incorporación; y basta reflexionar un poco sobre las habituales salidas de tono de los hombres para concluir que el resto de los seres vivos son dignos de ser convocados-incluidos en esta suerte de Arca de Noé literaria que es Bestiario: libro donde Arreola describe respetuosamente el sufrimiento del animal para revelar lo que somos. Y para sugerir, además, la cuestión de que sólo involucrando a la "otra mitad" (Hernández Quezada 2014b: 7), la experiencia humana será plena o integral, a tal punto que cada vez que pensemos en nuestra singularidad como especie habremos de pensar en la de los demás animales, indepen- 
dientemente de la clasificación a la que pertenezcan. Igualmente, dicha concepción aclara el porqué de la diversidad de Bestiario y su tratamiento dialógico; un tratamiento que, para expresarlo con claridad, indaga en las particularidades de la animalidad, sobre todo a la luz del espectro distorsionante de la modernización y sus efectos materiales. En pocas palabras, este objetivo expresa el que Arreola aluda a la crisis de la concepción sacralizadora, propia de muchas comunidades indígenas del país (México) y apueste por el recordatorio inquietante de que la sociedad actual debe parte importante de su desarrollo al sacrificio de los animales; al sacrificio racional, ordenado, silente, de tales entes.

En consecuencia, en el "Prólogo" de Bestiario, Arreola plasma su visión acerca del sufrimiento fáunico, ese "impulso de compasión, incluso si a continuación es ignorado, reprimido o negado, mantenido a raya" (Derrida 2008: 45). Tras mencionar algunas cuestiones que se deniegan o se pasan de largo, el "Prólogo" dice:

Ama al prójimo desmerecido y chancletas. Ama al prójimo maloliente, vestido de miseria y jaspeado de mugre.

Saluda con todo tu corazón al esperpento de butifarra que a nombre de la humanidad te entrega su credencial de gelatina, la mano de pescado muerto, mientras te confronta su mirada de perro.

Ama al prójimo porcino y gallináceo, que trota gozoso a los crasos paraísos de la posesión animal.

Y ama a la prójima que de pronto se transforma a tu lado, y con piyama de vaca se pone a rumiar interminablemente los bolos pastosos de la rutina doméstica (Arreola 1996: 9).

Con la idea de señalar varios aspectos relativos a la animalidad, Arreola plantea en el "Prólogo": 1) la necesidad de concebir esta variable en su justa medida; es decir, determinada por una realidad natural, no culturizada, cuyo dinamismo habitual se muestra desnudo, ajeno a los intereses humanos, y en franca dependencia del entorno físico en el que se desenvuelve -en el que se ensucia-, dadas las condiciones inherentes a su hábitat; 2) la urgencia de reconocer el sacrificio fáunico: un sacrificio cotidiano, muchas veces generalizado, gracias al cual el desarrollo de los hombres es factible, en tanto ese "esperpento de butifarra" es la muestra 
fehaciente de una concepción y utilidad pragmáticas que pauta muchos de nuestros procesos de consumo; 3) la idea de comprender al ser no humano en cuanto elemento vital, en cuanto elemento reproductor, que prioriza los flujos del bios, pues en su día a día también dicho ser está influido por los instintos, antes que por los condicionamientos simbólicos de la sociedad, y 4) la obligación de los lectores de ubicarnos, en cierto sentido, en el escenario inestable de la animalidad, de vernos con los mismos ojos, debido a que son muchos los elementos compartidos con la "otra mitad", independientemente de nuestro desarrollo neurológico o de nuestro miedo histórico a la desnudez.

En ese tenor, el planteamiento de Arreola se sustenta en una valoración dialógica, comprensiva, que parte, según sus términos, del amor: sentimiento equivalente al cariño, a la contemplación, a la celebración del ser no humano y, para el caso, al motor de una pieza literaria que pide al lector admitir la diferencia, el sentido de la misma, en aras de alcanzar una concepción más compleja y profunda de la realidad. Dice Arreola, en el "Prólogo": "Ama al prójimo desmerecido [...] Saluda con todo tu corazón al esperpento [...] Ama al prójimo porcino y gallináceo", lo cual implica, esencialmente, la idea de involucrar-redimir al animal y, como lo hace Rubín, mostrar lo invisible, lo violentado, sólo que enfatizando el devenir moderno de la fauna, en muchos casos sacrificada de mil maneras, dignas e indignas, so pretexto de satisfacer las necesidades habituales de la civilización (Hernández Quezada 2012: 129).

\section{La zoofilia como sacrificio en dos novelas}

En Morir en el golfo (1989) de Héctor Aguilar Camín y La torre y el jardín (2012) de Alberto Chimal, las coincidencias con respecto al uso del animal hacen pensar en una variable de la cosificación sacrificial: la zoofilia. O sea, si bien sus planteamientos centrales van por caminos diferentes (en la primera hablamos de una obra profusamente política que gira en torno a las prácticas habituales de la clase gobernante priísta y en la segunda, de una novela híbrida a medio camino entre la ciencia ficción y la fantasía), ambas refieren esta suerte de sacrificio fáunico luego de detenerse en la 
descripción detallada de diferentes prácticas sexuales mantenidas entre seres humanos y no humanos.

Indiscutiblemente, en ambos casos se parte de la idea del sometimiento animal, pero con la particularidad de que en Morir en el golfo se subrayan las connotaciones de tal relación en el contexto simbólico del medio rural, al amparo de los usos y costumbres indígenas; criterio que, de modo evidente, diverge del de La torre y el jardín, donde la zoofilia se efectúa con violencia en el contexto económico del medio urbano o, planteado de forma más específica, en el de un edificio citadino, en apariencia normal, que tras bambalinas funciona como burdel y negocio gore concebido para satisfacer las necesidades sexuales de quienes, displicentes, acuden a él. Esto, por sí mismo, reitera un acercamiento provocativo a la utilización del animal en el que, de nuevo, comprendemos que dicho ser es sometido al poderío devastador de los hombres sin que existan justificaciones racionales de por medio que expliquen el porqué de tal vejación, ni mucho menos formen parte de una suerte de lógica superior, de carácter trascendental, que consienta el sacrificio del ente no humano. Sin embargo, tanto en una como en otra novela resulta evidente que las implicaciones del uso fáunico se vinculan con la zoofilia y eso se constituye en algo fundamental que abona a la captación de un sentido: aclaremos, de aquél donde entran en juego los hábitos culturales (Morir en el golfo) y/o las perversiones individuales, denegadas por el mundo racionalizado de lo social (La torre y el jardín). Por este motivo, la propuesta de sus autores reitera el rol menor, diezmado, limitado, del animal, especialmente si se toman en cuenta no sólo las prácticas sexuales o íntimas a las que se le somete, sino además sus desenlaces, casi siempre perjudiciales-sacrificiales para el ente no humano y las cuales se traducen en un sinfín de mutilaciones, trastornos y ultrajes.

En Morir en el golfo, el planteamiento anterior se patentiza cuando Aguilar Camín describe el tipo de relaciones dadas entre las comunidades indígenas y los políticos, insistiendo en el problemático asunto de que las prácticas culturales resultan determinantes en el ejercicio efectivo del poder, de suerte que quien se dedica a la administración pública debe soportar a priori el viacrucis de toda clase de padecimientos personales, probablemente incomprensibles desde el punto de vista individual, por no mencionar el carecer de escrúpulos especistas al infligir dolor y sufrimien- 
to en el ser no humano. Tal como se lee, en todo caso, en el capítulo seis, "El sacrificio de la venada", la práctica vejatoria se dirige al animal, más que al hombre, por causa de que, al igual que en El canto de la grilla, éste es utilizado unidireccionalmente en el escenario de la actividad simbóli$\mathrm{ca}$, importante para una comunidad que se desenvuelve con criterios diferentes a los del mundo occidental. Visto así, el capítulo seis de Morir en el golfo resulta fundamental para entender las interacciones que se dan entre las clases hegemónicas y subalternas pero, también, entre las culturas que se desenvuelven en países plurales como México.

En ese orden de ideas, cuenta Rojano —uno de los personajes principales de Morir..., dedicado a la política - la experiencia que tuvo al iniciar su campaña electoral y entrar en contacto con los líderes de una comunidad indígena del estado de Veracruz (no se especifica cuál), quienes le plantearon el siguiente reto; dice:

Pues órale. Nos fuimos una tarde a la casa del mayordomo del barrio, todos muy ceremoniosos y ladinos los cabrones y nos sentamos ahí a platicar y un buchecito de mezcal para romper el hielo [...] Todos sonrientes y ceremoniosos, auténticamente como chinos. Bueno, se pusieron a mi alrededor y el principal del barrio repitió que era regalo muy de apreciar para el jefe de la autoridad municipal y que aquí lo daban justamente en señal de aprecio. Acabó de griIlarme y sale del monte otro cabrón jalando del cordel una venada, un animal precioso, de poca alzada, todavía sin desarrollar a plenitud, y bastante tranquila para ser venada. Van y la amarran en la estaca y se hacen a un lado y me invitan con un ademán a acercarme a la venada. Pues voy y me le acerco a la venada y le acaricio el hocico y el lomo y muchas gracias señor mayordomo y muchas gracias señores del barrio de San Felipe. Y conforme voy diciendo esto los voy viendo que me miran como desconcertados y vuelve a hacerme el mayordomo el ademán de que siga adelante (Aguilar Camín 1989: 116-117).

En estas líneas se destacan varias cosas, entre ellas la que alude a la obligatoriedad del acto simbólico-zoofílico, concebido como rito de iniciación y reconocimiento social. Y tan es así que, al instante, los "ceremoniosos" que participan en tal costumbre se sienten extrañados al ver cómo Rojano muestra repulsión o rechazo hacia la "venada", entre otros motivos porque no comprenden que alguien que pretende gobernarlos evada el significado de un "sacrificio" animal-humano, que si algo revela 
es el determinismo de las concepciones culturales; su importancia en el fortalecimiento del vínculo establecido entre seres humanos de diferentes razas y cosmovisiones. Lo cierto es que, en el afán de ejercer el poder y, llegado el momento, contar con el apoyo requerido de los indígenas y sus líderes, el intimidado Rojano se sacrifica con resquemor, con pena, sin creer en lo que hace, debido a que carece de mejores opciones para legitimar sus intereses frente a los demás. De modo que, seguidamente, la aceptación de su destino, ante las miradas de quienes lo observan como "chinos" ("sonrientes" a más no poder) colige para él una degradación, no tanto inclusiva como individual, puesto que la "venada", si bien es la figura disruptiva en este pasaje, francamente se convierte en una entidad menor, secundaria, que incluso, en opinión de Rojano, se muestra "bastante tranquila" e indiferente ante la humanidad.

Como se desprende del pasaje, Aguilar Camín, con buen ojo antropológico-periodístico, describe el rol pragmático del político mexicano al trasladarlo al escenario ajeno de un rito de iniciación, el cual, a todas luces, exige entrar en contacto íntimo con el animal. Un rito zoofílico que, planteado desde la perspectiva de la conexión simbólica, maximiza el papel transformativo del ser humano luego de que éste experimente un "cambio de estatus" y sea apartado de la "existencia normal" (Leach 1989: 107). Porque, en efecto, dicho "cambio", inquietante para el propio Rojano, permite que forme parte de la comunidad indígena o que, por lo menos, se identifique con ella. Pero además, que observe ampliamente las cosas desde otra-nueva perspectiva y entienda, de súbito, que la "venada" también es una "hembra", según la lógica establecida del paradigma cultural-indígena: una lógica que favorece el darse "gusto[s]" (Aguilar Camín 1989: 118) como el que aquí se ha descrito, extraño y perjudicial para la integridad del animal.

Consecuentemente, la participación de Rojano en este rito se convierte en un desvelamiento, que lo impulsa a expresar lo siguiente: "Y entonces me cae de verdad el veinte, cabrón: ¡Querían que me cogiera a la venada! No sólo eso, sino que ahí mismo enfrente de ellos. ¿Te das cuenta? Entonces me acuerdo de que el cabrón de Pizarro comparó a Anabela con un venado, de modo que me están ofreciendo al doble de mi mujer, al nagual de mi mujer, ¿entiendes?" (Aguilar Camín 1989: 118). 
En La torre y el jardín tenemos otro planteamiento, a pesar de que en esta novela se trabaje sobradamente el tema de la relación sexual entre hombres y animales. Obra desquiciante que retrata como pocas la imagen perversa de la degradación fáunica, La torre y el jardín plantea con insistencia la estampa terrible de la "posesión animal", al tiempo que enfatiza los alcances de la ¿creatividad? humana cada vez que parte del supuesto monológico de que el animal, en tanto criatura vital, es una entidad controlable, de fácil manipulación.

Para Chimal, además, tal concepción del elemento fáunico se inscribe en la lógica productiva del capitalismo tardío, que así como carece de recatos al justificar, fría y calculadoramente, la muerte cotidiana de cientos de miles de animales (la industria cárnica), del mismo modo favorece la existencia de prostíbulos zoofílicos-citadinos a los cuales acuden quienes experimentan placer al someter, sexualmente, a la "otra mitad". Pues ese es uno de los puntos mayormente desarrollados por Chimal en su novela: presentar el modo destructivo en el que los seres humanos utilizan al animal, sin importar que al final se le deseche como producto de consumo o sufra físicamente todo tipo de martirios tras hallarse encerrado en ese espacio macabro que es "El Brincadero": burdel salvaje, de afectaciones bárbaras, donde los seres humanos compactan el sufrimiento constante, recurrente, del resto de las especies (Ramírez 2018: 5).

Siendo precisos, "El Brincadero" no es otra cosa sino el espacio de la denegación fáunica, el templo capitalista del salvajismo humano, imaginado y puesto en marcha para rendir culto al dinero, sólo que con la insistencia asfixiante de que tal honra se alcanzará con la muerte o el sacrificio permanente del animal. Desde luego, aludimos a un sacrificio preciso, falto de simbolismos o justificaciones trascendentales, diferentes a las reveladas en El canto de la grilla o, en menor medida, en Morir en el golfo. Un sacrificio indolente, motivado por el psicópata de clóset, dispuesto a pagar fortunas para calmar su sed de sangre o si no, por el inventivo-industrioso que juega con el dolor animal por placer y diversión.

Definitivamente, la evidencia del registro puntual de este sacrificio, practicado en el espacio sombrío de un burdel, amén de la vocación transgresiva, zoofílica, que presenta y violenta la autonomía animal, son referentes sustantivos y reconocibles de La torre y el jardín: novela agresiva, 
discordante, fiel a los dinamismos de la época actual, en la que, desde la raíz, desaparecen los visos del humanismo histórico, justamente por la inercia que retrata de los mecanismos destructivos de la sociedad. Luego entonces, el ferviente y sostenido propósito de Chimal por evidenciar la crisis del nexo humano-no humano se constituye en el ejercicio intenso y demoledor de una literatura crítica, problemática, que jamás renuncia a las claves de su propuesta y, no obstante, intensifica la imagen dolorosa de la degradación fáunica a tal grado o nivel que al concluir la lectura de La torre y el jardín es muy probable que los lectores se hagan múltiples preguntas sobre su relación con la animalidad.

A la par, esto explica la estructuración de la obra, la cual encierra su trama en las cuatro paredes de un edificio terrorífico, el mismo que sintetiza múltiples variables del sacrificio no humano. Se entiende por tanto que Chimal, en las primeras páginas de La torre y el jardín, describa pulcramente las características del lugar aludido, a la manera de una especie de anuncio publicitario que muestra los aspectos más agradables del producto a vender:

En la esquina de las calles de Nicolás Bravo y Miguel Hidalgo, en el centro de la ciudad de Morosa, hay un edificio. Su aspecto no es deslumbrador: por fuera parece tener siete pisos de altura moderada, y es poco más que una caja de concreto, lisa y sin adornos. La impresión se acentúa porque no hay ventanas antes del quinto o sexto piso y el gris constante bajo esos primeros cristales es una superficie enteramente plana: uniforme.

El negocio que funciona en el edificio no tiene nombre, pero muchas personas (sobre todo, cuando hablan del lugar en secreto, o entre risas nerviosas) lo Ilaman "El Brincadero" [...]

Ese nombre, que es simple y vago al mismo tiempo, no es tan diferente del de otros establecimientos de su mismo giro en la ciudad y fuera de ella (2012: 21).

La descripción que Chimal hace de "El Brincadero" no es gratuita; apela a la construcción de ese espacio físico-narrativo que, además de situar la historia contada en el ámbito reconocible de lo urbano, le brinda una posibilidad, en particular: concentrar el tipo de suplicios animales que los clientes reclaman y que, en grado extremo, evidencian las capacidades innatas de los seres humanos para ocasionar dolor y padecimientos 
en la "otra mitad". De tal modo, en La torre y el jardín la descripción de los martirios fáunicos obedece a una articulación archivística que detalla las claves de un libro taxonómico que — palabras más, palabras menosfunciona como manual para favorecer el sacrificio animal; como manual utilitario, pragmático, donde es fundamental resumir las claves monológicas de una organización textual que comienza con el nombramiento del animal para, después, explicar sus beneficios, tanto físicos como sexuales. Para muestra, baste un botón:

LOS PELíCANOS. Como otras aves, los pelícanos se emplean para las tareas más simples - las inserciones y los frotamientos-, para otras acciones y fantasías.

Una de las más solicitadas tiene que ver, al contrario de tantas otras cosas en el negocio, con la tradición [pues] según dice la leyenda, los pelícanos se picotean entre ellos solos aquí, en la pechuga, para alimentar con eso a sus hijos, pero eso no es cierto: no hay ningún pelícano que haga eso. Pero los que creen esto también aseguran que los pelícanos son como Jesús, porque se sacrifican por sus hijos, como Dios, y entonces vienen acá con picahielos y taladros y quién sabe qué más traen y que juega a que son como... (Chimal 2012: 39).

Mediante esta clase de entradas, frecuentes a lo largo de La torre y el jardín, Chimal entreteje una historia desquiciante y extraña que abrevia, literariamente, múltiples formas del sacrificio animal. Anotemos que, interesado en explorar la faceta más destructiva del ser humano, Chimal deja de lado los procedimientos simbólicos del rito o ritual, en pos de adentrarse en el territorio caótico de esa pesadilla que jamás explica o justifica los beneficios de la crueldad, ni mucho menos el porqué de la pulsión acendrada en algunos a volcarse contra quienes se encuentran en clara desventaja tras exhibir su "desnudez".

\section{Nota final}

El propósito de este trabajo ha sido comentar, sucintamente, ejemplos del modo en el que el tema del sacrificio animal se concibe por parte de algunos autores mexicanos como Rubín (El canto de la grilla), Arreola (Bestiario), Aguilar Camín (Morir en el golfo) y Chimal (La torre y el jardín); autores que, por un lado, insisten en la relación de este tema con los usos 
y costumbres ancestrales y por otro, con los procedimientos habituales del sistema económico de consumo y producción. En virtud de ello, entendemos los cruces de nuestra literatura con dichas cuestiones, insistiendo en que, en los casos mencionados, la labor del escritor consiste en generar imágenes violentas en torno al maltrato de la "otra mitad", las cuales no pasen desapercibidas y contribuyan a la reflexión profunda y necesaria de que muchos de nuestros actos culturales implican el sufrimiento de las especies no humanas. Un sufrimiento físico, cuando no cerebral, que se justifica en función de los procedimientos de interacción simbólica, determinada, sabemos, por el influjo de factores diversos, como la necesidad de reverenciar a una fuerza superior o fortalecer los nexos existentes al interior grupal.

En otro tenor, planteamos el argumento de que la cosificación fáunica, resultado de los hábitos modernos, contribuye al tratamiento de una variable sacrificial, que poco o nada se vincula con el orbe de lo sagrado. Autores como Arreola o Chimal ofrecen una estampa divergente de la muerte o del sufrimiento animal, justamente al invocar la lógica disfuncional de la modernidad y revelar, de ese modo, el vacío de una época que desmanteló el paradigma de lo religioso en nombre de la razón. Las consecuencias, al menos para la "otra mitad", de esta realidad, conllevan el padecimiento de un sinfín de prácticas violentas o vejatorias, carentes de significación trascendental e inscritas en la vaciedad de un mundo deshumanizado, regido por el dinero y la sobreexplotación del orbe natural.

Vista así, la utilización literaria del ser no humano, a partir de los escritores analizados, es una utilización dialógica y problemática en vista de que parten de la advertencia de que la sola mención de este ser no basta para identificar lo que gira en su derredor y que, en términos generales, tal procedimiento es insuficiente para su cabal comprensión. Igualmente, semejante uso precisa el surgimiento de un mensaje disruptivo que, de forma abierta o velada, manifiesta su vocación animalista en el contexto de las letras del país. Hablamos, en efecto, de un tipo de literatura asertiva, analítica y fustigante, que muestra la complejidad del ente fáunico (de sus manifestaciones y procesos habituales), al tiempo que el de la relación sostenida por los seres humanos con éste: relación histórica que, conviene señalar, una vez más, modela prácticas individuales y colectivas que 
legitiman procesos selectivos de desmantelamiento y destrucción. En tal esquema, advirtamos la ubicación de estos textos y no olvidemos que su comunicación discursiva se dirige, especialmente, a estropear conceptos y juicios sobre la estabilidad o mejor, a establecer variables críticas del entorno que, potenciadas por el código creacional, vivifican imágenes soterradas, dignas de atención.

La búsqueda de tales objetivos, lleva a pensar en los matices de los escritores analizados, en sus apuestas animalsonantes; a la vez, en la importancia del tema tratado, el cual, de inmediato, nos traslada a un problema mayor: el de la concepción que tenemos de lo no humano o, más bien dicho, el del modo en que se entrecruzan dos manifestaciones vitales cuando una, pareciera ser, ejerce su poderío extremo, dejando poco o nulo espacio para la integración.

No cabe duda de que los casos mencionados potencian los alcances estéticos de la literatura mexicana y que sus estructuras narrativas, en general, establecen contactos directos con las reflexiones culturalistas de Girard o Geertz, o filosóficas y deconstructivas de Derrida; situación que, bien vista, creemos, hace de sus obras piezas interesantes y sugerentes para captar lo que no percibimos con respecto al sacrificio animal; un padecimiento colectivo y silente, un uso pragmático del bios que, forzado por las circunstancias, exhibe su precariedad y no sólo eso, también los matices estéticos de un ejercicio poderoso, intenso y demoledor, concebido para enfatizar la relación de los hechos descritos al captar los ecos agónicos y sufrientes del animal. Visto como sujeto importante que fractura la estabilidad del relato o que modifica, para el caso, la percepción del ser racional, entendemos que escritores como Rubín, Arreola, Aguilar Camín o Chimal asimilan el poderío del ente fáunico y que la singularidad de sus planteamientos, veraces y trastornadores, estriba en señalar las implicaciones dominantes de nuestro vínculo con la "otra mitad" y su "mala sombra".

\section{Bibliografía}

Aguilar Camín, Héctor. Morir en el golfo. México: Cal y Arena, 1989.

Arreola, Juan José. Bestiario. México: Joaquín Mortiz, 1996. 
Bernal, Rafael. Su nombre era Muerte. México: Jus, 1947.

CABRera Díaz, ANA. El ritual de sacrificio de animales en la cultura ibérica: una perspectiva arqueológica. Tesis doctoral. Madrid: Universidad Complutense de Madrid, 2010.

Chimal, Alberto. La torre y el jardín. México: Océano, 2012.

Derrida, Jacques. El animal que luego estoy si(gui)endo. Trad. Cristina de Peretti y Cristina Rodríguez Maciel. Madrid: Trotta, 2008.

ESPINASA, José MARía. La literatura mexicana del siglo xx. México: El Colegio de México, 2016.

GeerTz, Clifford. La interpretación de las culturas. Trad. Alberto L. Bixio, Barcelona: Gedisa, 1997.

GIRARD, RenÉ. La violencia y lo sagrado. Trad. Joaquín Jordá. Barcelona: Anagrama, 1983.

Ferrero CÁrdenas, Inés. "Una violeta de más, de Francisco Tario: crueldad, humor y praxis", en Valenciana. Estudios de Filosofía y Letras. Guanajuato, 4 (jul.-dic. 2009): 161-175.

HeRnÁNDEZ LOREDO, AdRIANA. "Una versión científica, ancestral y de la condición humana, a través del juego analógico de Juan José Arreola, en Bestiario", en Mitologías Hoy. Revista de Pensamiento, Crítica y Estudios Literarios Latinoamericanos. Barcelona, 5 (verano 2012): 107-118.

Hernández Quezada, Javier. "De risas y bestiarios", en Escritos. Revista del Centro de Ciencias del Lenguaje. Puebla, Pue., 45 (enero-junio de 2012): 123-139.

Hernández QuezadA, JAVIer. Fauna. Un bestiario de la literatura mexicana. Mexicali, B. C.: Universidad Autónoma de Baja California, 2014a.

Hernández Quezada, Javier. "Notas sobre un bestiario en Poeta en Nueva York", en Argus-a. Artes \& Humanidades. California-Buenos Aires, IV-14 (octubre 2014b): 1-14.

Hernández Quezada, JAvier. "El matrimonio de los peces rojos: el vínculo humanoanimal", en Graffylia. Revista de la Facultad de Filosofía y Letras. Puebla, Pue., 24 (enero-junio 2017): 71-78.

JÁuregui, Jesús. Coras. Pueblos indígenas del México contemporáneo. México: Comisión Nacional para el Desarrollo de los Pueblos Indígenas / Programa de Naciones Unidas para el Desarrollo, 2004.

LeACH, EDmund. Cultura y comunicación. La lógica de la conexión de los símbolos. Trad. Juan Oliver Sánchez Fernández. Madrid: Siglo XXI de España, 1989.

Libonati, Fernando. "Sacrificio y comunidad. El animal como parergon", en Revista Latinoamericana de Estudios Críticos Animales. Buenos Aires, IV-1 (junio 2017): 34-60.

Ramírez, Diana. "Imaginación y símbolo: La torre y el jardín, de Alberto Chimal", en Córima. Revista de Investigación en Gestión Cultural. Guadalajara, 3-4 (enero-junio 2018). DOI:10.32870/cor.a3n4.7105.

Ricoeur, Paul. Teoría de la interpretación. Discurso y excedente de sentido. Trad. Graciela Monge Nicolau. México: Siglo XXI, 1998.

Rubín, RAmón. El canto de la grilla. México: Fondo de Cultura Económica / Secretaría de Educación Pública, 1985. 
Serratos, Francisco. "¿Cómo rescatar a un escritor? El caso de Rafael Bernal”, en Cuadernos Fronterizos. Ciudad Juárez, 39 (enero-abril 2017): 7-10.

SuÁrez, Ernesto joaquín, luciana Carrera Aizpitarte y Micaela Anzoátegui. "Adiós a la torre de marfil o sobre cómo abandonar la tesis de la excepción humana en la filosofía", en Revista Latinoamericana de Estudios Críticos Animales. Buenos Aires, V-1 (enero-junio 2018): 1-20.

TARio, Francisco. "Ragú de ternera", en Una violeta de más. México: Joaquín Mortiz, 1968.

TURNER, VICTOR W. El proceso ritual. Estructura y antiestructura. Trad. revisada por Beatriz García Ríos. Madrid: Taurus, 1988.

YurkiÉVICH, SAúl. "Humana animalidad en Juan José Arreola", en América. Cahiers du CRICCAL. París, 18-1 (1997): 195-201.

Francisco Javier HeRnÁNDEZ QueZadA

Doctor en Literatura Española e Hispanoamericana por la Universidad de Salamanca. Es profesor-investigador de carrera en la Facultad de Humanidades y Ciencias Sociales de la Universidad Autónoma de Baja California. Es autor de los libros Entornos y periferias (2016), Historias (...) (2016), Kanji (2014), Fauna. Un bestiario de la literatura mexicana (2014), La imago mexicana en la obra de José Lezama Lima (2011), Lo mexicano en Paradiso (2007) y "No está en mis manos escribir sin vehemencia". Autobiografía y picaresca en las "Memorias" de fray Servando (2003), con el cual obtuvo el Premio Nacional de Ensayo Joven José Vasconcelos. Es miembro del Sistema Nacional de Investigadores (Conacyt) y del Cuerpo Académico Literatura, discurso e identidad con registro en PROMEP. Desarrolla las líneas de investigación literatura y animalidad, literatura del norte de México y literatura latinoamericana contemporánea. 